\title{
Performance Study of Installed an I-65 Type Cylinder at the Upstream of Returning Blade of Savonius Wind Turbine, Comparison with Conventional Savonius Wind Turbine
}

\author{
Gunawan Sakti and Triyogi Yuwono
}

\begin{abstract}
Savonius wind turbine has many advantages over others in that its constructions are simpler and cheaper; it is independent of the wind direction and has a good starting torque at lower wind speeds. However, this type of wind turbine has the lowest performance compared to others types of wind turbine. That is why various studies have been done to improve the performance of the turbine Savonius. This paper is proposed in order to increasing the performance of Savonius wind turbine experimentally by installing an I-65 ${ }^{\circ}$ type bluff body at the upstream of returning blade of the turbine. The experiments are carried out for free stream velocity $(U)$ of $7 \mathrm{~m} / \mathrm{s}$ corresponds to Reynolds number of about 127.000 (based on the characteristic length of $d=2 D$-e and free stream velocity $(U)$ from fan used. The center to center distance between the $I$ $65^{\circ}$ type cylinder and the returning blade turbine relative to turbine blade diameter S/D specified for 1.4. The diameter of I$6^{\circ}$ type cylinder relative to turbine blade diameter is 0.5 . The result of experimental show that in general compared to conventional Savonius wind turbines, the placement of $I-65^{\circ}$ type cylinder in front of the returning blade of the Savonius wind turbine is effective for improving turbine performance. The results of this experiment show that for $\operatorname{Re}=127,000$, the power coefficient of the turbine with the $I-65^{\circ}$ type cylinder is greater than when the turbine has no I-65 ${ }^{\circ}$ type cylinder or conventional Savonius wind turbine. Where in this condition, the maximum coefficient of power the Savonius turbine (CP) with $\mathrm{I}-65^{\circ}$ type cylinder can actually increase to $25.66 \%$ compared to the turbine without the $\mathrm{I}-65^{\circ}$ type cylinder; this is obtained for Tip Speed Ratio of 0.76 .
\end{abstract}

Keywords-I-65 Type Cylinder, Savonius Wind Turbine Performance, Upstream Of Returning Blade.

\section{INTRODUCTION}

$\mathrm{W}$ ind energy is a freely available natural resource that is abundant and available over the years. But unfortunately wind speed in Indonesia is relatively low, which is about 4-7 m/s. The appropriate turbine for low wind speed is the Savonius turbine. This turbine is a vertical pivot turbine type, Vertical Axis wind Turbine (VAWT). The Savonius turbine is one example of a drag type turbine. The phenomenon of flow across the Savonius turbine is the use of drag force to improve the performance of the turbine. The flow will cross the 2 (two) side of the advancing blade and the returning blade. The difference of drag force between the returning blade and the advancing blade will result in a total drag to rotate the Savonius turbine. The advantages of this type of drag turbine are the self-starting ability with a small fluid velocity, so there is no need for external push support; it is very suitable for the region of Indonesia which has a relatively low average speed. However, this type of wind turbine has the lowest performance compared to others types of wind turbine. That is why various studies have been done to improve the performance of the turbine Savonius. Fig 1. Shows the coefficient power function TSR $(\lambda)$ different types of wind turbines photographs. The proceedings will be printed in black only. Keep it in mind when the use of color is unavoidable.

The performance of Savonius rotor has been studied by many researchers from 1977 until 2018 in order to determine the optimum design parameters of this rotor. In the following, the main trends in these studies are summarized and discussed.

Gunawan Sakti and Triyogi Yuwono are with Department of Mechanical Engineering, Institut Teknologi Sepuluh Nopember, Surabaya, 60111, Indonesia. E-mail: triyogi@me.its.ac.id.

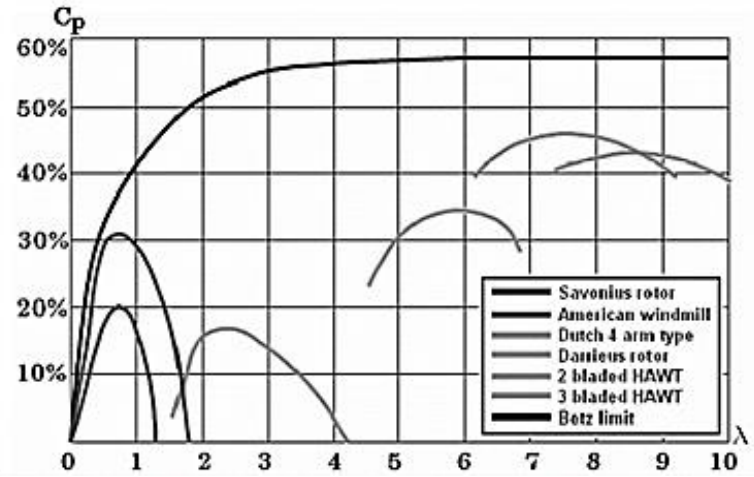

Figure 1. Power coefficient function Tip-Speed Ratio $(\lambda)$ for various Wind Turbines [1].

Reducing the drag coefficient by placing the bluff body type I- $65^{\circ}$ in front of the main cylinder as a passive control tested by Triyogi et al [2]. I-type bluff bodies with different cutting angles of $\theta \mathrm{s}=0^{\circ}$ (circular), $10^{\circ}, 20^{\circ}, 30^{\circ}, 45^{\circ} \circ, 53^{\circ}$, and $65^{\circ}$ were located in front and at the line axis circular cylinder at a spacing $\mathrm{S} / \mathrm{D}=1.375$. The experiment obtained the decrease of drag coefficient $\left(C_{D}\right)$ up to $52 \%$ at the Reynolds number $5.3 \times 10^{4}$. Experimental investigation of the flow characteristics of a bluff body cut from a circular cylinder is reported by Aiba $\&$ Watanabe [2]. The volume removed from the cylinder is equal to $d / 2\left(1-\cos \theta_{s}\right)$, where $d$ and $\theta_{s}$, are the diameter and the angular position (in the case of a circular cylinder, $\theta_{s}=0^{\circ}$ ), respectively. $\theta_{s}$ ranged from $0^{\circ}$ to 72.5 ${ }^{\circ}$ and $\operatorname{Re}$ (based on $d$ and the upstream uniform flow velocity $\mathrm{U}_{\infty}$ ) from $2.0 \times 10^{4}$ to $3.5 \times 10^{4}$. It is found that singular flow around the cylinder occurs at around $\theta_{s}=53^{\circ}$ when $\operatorname{Re}>2.5 \times 10^{4}$, and the base pressure coefficient ($\mathrm{C}_{\mathrm{pb}}$ ) and the drag coefficient $\mathrm{C}_{\mathrm{D}}$ take small values compared with those for other $\theta_{s}$. Tsutsui \& Igarashi [3] 


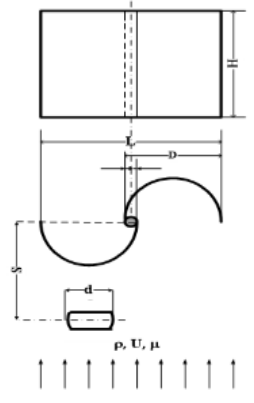

(a)

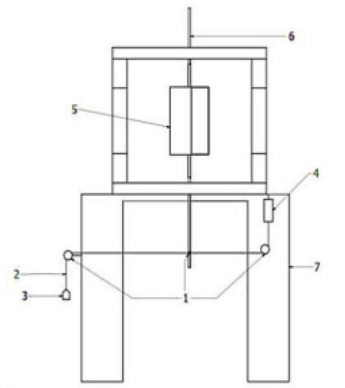

(b)
Figure 2. (a). The arrangement of Savonius wind rotor with I- $65^{\circ}$ type cylinder placing in front of Returning Blade. (b). The schematic diagram of dynamic torque measurement.

studied experimentally the flow control around a circular cylinder in air-stream with a rod that set upstream of the circular cylinder. The diameter of cylinder, $D$, was $40 \mathrm{~mm}$ and the diameter of rod, $d$, ranged from 1 to $10 \mathrm{~mm}$. The distance between the axes of the circular cylinder and rod, $L$, was $50-120 \mathrm{~mm}$. The Reynolds number based on $D$ ranged from $1.5 \times 10^{4}$ to $6.2 \times 10^{4}$. The optimum conditions of the drag reduction are $\mathrm{d} / \mathrm{D}=0,25, L / D=1,75$ $-2,0$. The reduction of the total drag including the drag of the rod is $63 \%$ compared with that of a single cylinder.

Altan improve the performance of Savonius with placed the curtain upstream returning blade and significant increase achieved in the rotor performance by means of the curtain design [3]. Experiments of the curtain design have been conducted in three different dimensions when the Savonius wind rotor is static, and the highest values have been obtained with the curtain 1. The Power Coefficient $\left(\mathrm{C}_{\mathrm{p}}\right)$ increase up to $38.5 \%$ within curtain dimension $\ell_{1}=45 \mathrm{~cm}$ dan $\ell_{2}=52 \mathrm{~cm}$ and $\alpha=45^{\circ}$ dan $\beta=$ $15^{\circ}$. Mohammed et al, investigated experimentally in order to improve the output power of the Savonius turbine as well as the static torque, which measures the selfstarting capability of the turbine [4]. Both objectives achieved by the geometry of the blade shape (skeleton line) optimized in presence of the obstacle plate. Compared to a standard Savonius turbine, a relative increase of the power output coefficient by almost $40 \%$ is finally obtained at $\lambda=0.7$. The performance increase exceeds $30 \%$ throughout the useful operating range. The static torque is investigated and found to be positive at any angle, high enough to obtain self-starting conditions.

Mahmoud et al experimentally studied the different geometries of Savonius wind turbine in order to determine the most effective operation parameters [5]. It was found that, the two blades rotor is more efficient than three and four ones. The rotor with end plates gives higher efficiency than those of without end plates. Double stage rotors have higher performance compared to single stage rotors. The rotors without overlap ratio $(b)$ are better in operation than those with overlap. The results show also that the power coefficient increases with rising the aspect ratio $(a)$. Triyogi et al, have studied numerically about the effect of width of single curtain on the performance of Savonious wind turbine [6]. They proved that the installing of the curtain in front of the returning blade of the turbine for improving the performance of turbine is depend on the width of the curtain and the Reynolds number. For the width of the large curtain of $S / D=2.0$ at $\mathrm{Re}=90,000$ the performance of the turbine is estimated

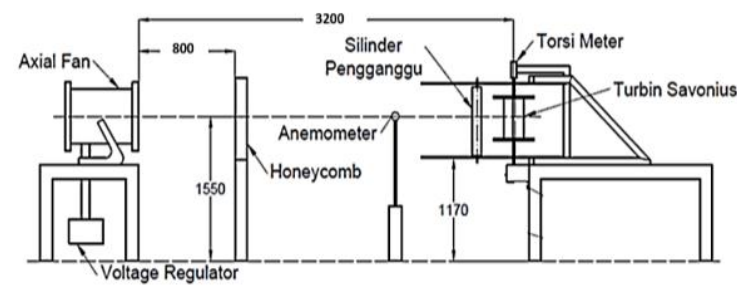

Figure 3. Schematic diagram of experimental set-up (dimensions: $\mathrm{mm})$.

lower than when the turbine without the curtain. For the same case, Triyogi et al, have also investigated experimentally the problem [7]. They also proved that the placement of the curtain plate at the upstream of the returning blade of the turbine for improving the performance of the turbine is depend on the width of the curtain plate and the Reynolds number. Where for the wider curtain $(\mathrm{S} / \mathrm{D}>1.4)$ at $\mathrm{Re}=90,000$ the coeficient of power turbine is less than when the turbine without the curtain plate. For this condition, the coefficient of power of the turbine with the curtain plate may fall to $60.8 \%$ of the turbine without the curtain plate, for $\mathrm{S} / \mathrm{D}=1.83$ at $\mathrm{Re}$ $=90,000$.

Based on above understanding, this paper is proposed in order to increasing the performance of Savonius wind turbine experimentally by installing an I- $65^{\circ}$ type bluff body at the upstream of returning blade of the turbine. The experimental is conducted by determined the distance between the axes of returning blade of turbine Savonius $\mathrm{S} / \mathrm{D}=1.4$ and at specified Reynolds Number.

\section{METHOD}

\section{A. Experimental arrangement}

Figure $2 \mathrm{a}$ shows the arrangement of Savonius wind turbine with a I- $65^{\circ}$ type bluff body placing in front of the returning blade, where the I-type cylinder is a small circular cylinder of diameter $(\mathrm{d})=76.2 \mathrm{~mm}$ cut at the both sides in parallel with the-y axis. The turbine made of plastic pipe (PVC) has the blade diameter of $D=6$ inches or approximately of $152.4 \mathrm{~mm}$ and height $H=300 \mathrm{~mm}$, with overlap $e=19 \mathrm{~mm}$. The $\mathrm{I}-65^{\circ}$ type cylinder is fabricated from plastic PVC whose height is $500 \mathrm{~mm}$ placed in the upstream of returning blade of the turbine with center to center distance relative to turbine diameter S/D of 1.2 to 2.2. The experiments are carried out for free stream velocity $(U)$ of $7 \mathrm{~m} / \mathrm{s}$ corresponds to Reynolds number of about 127,000 (based on the characteristic length of $\mathrm{d}=2 \mathrm{D}$-e and free stream velocity $(U)$ from fan used. Figure $2 b$ shows the dynamic torque of the turbine is measured by a brake rope dynamometer. This refers to research from [5]. This brake rope dynamometer contains of weighing pan, pulley, nylon string and spring balance. The spring balance and weighing pan is connected by a nylon string with diameter of $1.0 \mathrm{~mm}$, where the string was wounded one turn $\left(360^{\circ}\right)$ over the pulley.

Figure 3 shows the schematic diagram of experimental set-up, where Savonius wind turbine was located at 3200 $\mathrm{mm}$ from an axial fan (type CKE SPF-45, diameter $=450$ $\mathrm{mm}$, speed $=1800 \mathrm{rpm}$, air flow $=125 \mathrm{~m}^{3} / \mathrm{min}$, power $=$ 1700 Watt), and where at $800 \mathrm{~mm}$ in front of fan was positioned a honey comb to make the flow uniform possible. An anemometer Omega type HHF141 was used to measure flow velocity, this anemometer has the 


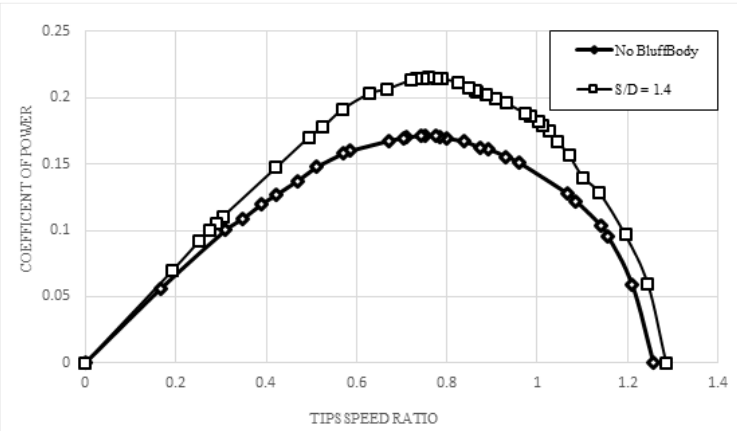

Figure 4. Evolution of the power coefficient of turbine as function of Tip Speed Ratio, for $\mathrm{S} / \mathrm{D}=1.4$ and $\mathrm{Re}=127.000$.

measuring range 1.5 to $35 \mathrm{~m} / \mathrm{s}$ with accuracy of $\pm 1 \%$. The rotational speeds have been measured on OMEGA series HHT12 optic tachometer equipment with the measuring range of 5 to $99,999 \mathrm{rpm}$ and the accuracy of tachometer equipment is $0.01 \%$. The torque meter of LUTRON model TQ-8800 having the measuring range of 0 to $147.1 \mathrm{Ncm}$ with accuracy of $0.01 \mathrm{~N} . \mathrm{cm}$ was used for measuring the static torque of turbine. The rotor shaft is supported by ball bearing type R12ZZ, where the seals are removed from bearings and bearings are washed in petrol to remove the grease before mounting and also the bearings are greased with multi proposed lubricant in order to avoid friction. The spring balance (type Nagata C-5) has the measurement range of 0 to 10.000 gram with resolution of \pm 50 gram. The mass balances are calibrated by a balance of type Shimadzu ELB300 having the measuring range of 0 to 300 gram with accuracy of \pm 0.01 gram. The rotor was loaded gradually (adding 20 gram of mass each time) by the rope break dynamometer from no load condition to the highest load that stopped the rotor, it gives Tip Speed Ratio in range of about 0 to 1.3. The spring balance reading and rotational speed measured by tachometer were recorded at these each condition used to calculate the dynamic torque. Finally the maximum value of dynamic torque at the rotational speed corresponding are chosen to calculate the maximum power of rotor turbine, which is evaluated to analyze the performance of the turbine.

\section{B. Measurement and Computation}

The mechanical power for the tested Savonius rotor is determined by measuring the mechanical torque on the rotating shaft and rotational speed at specified Reynolds Number about 127.000. The Reynolds number determined based on wind speed and length of characteristic turbine Savonius with the equation below:

$R e=\frac{\text { inertia forces }}{\text { viscous forces }}=\frac{\rho V L}{\mu}=\frac{\rho V(2 D-e)}{\mu}$

where $L$ is the length of characteristic turbine savonius, $D$ is the turbine blade diameter $(m)$ and $e$ is the diameter overlap $(m), \rho$ is air density $\left(\mathrm{kg} / \mathrm{m}^{3}\right), \mu$ is dynamic viscosity ( $p a . s), V$ is freestream velocity $(\mathrm{m} / \mathrm{s})$. From the measured values of mechanical torque and rotational speed, the mechanical power $\left(P_{m}\right)$ can be estimated as follows:

$$
P_{m}=T \omega
$$

Where $T$ is mechanical torque $(N . m), \omega$ is angular velocity $(\mathrm{rad} / \mathrm{s})$. The mechanical torque is obtained by:

$$
T=F r
$$

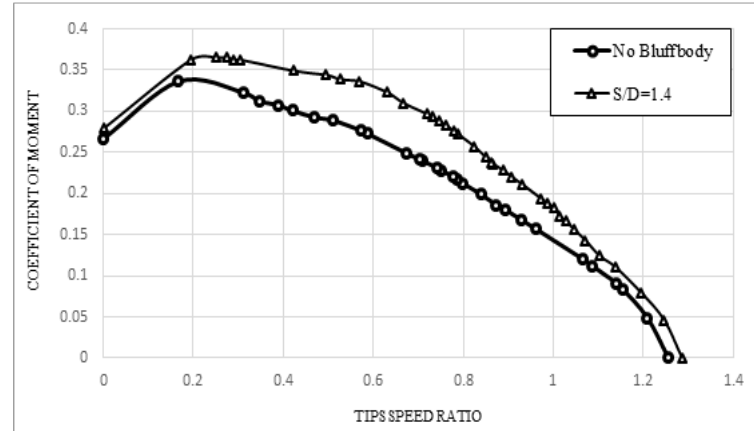

Figure 5. Evolution of torque coefficient of turbine as fuction of tips-speed ratio for $\mathrm{S} / \mathrm{D}=1.4$ and $\mathrm{Re}=127.000$

Where $r$ is the pulley radius and $F$ is the force acting on the rotor shaft obtained in $(N)$ by:

$$
F=(m-s) g
$$

Where $m$ is the mass loaded on the weighing pan in $\mathrm{kg}, \mathrm{s}$ is the spring balance reading in $k g$ and $g$ is the gravitational acceleration $\left(\mathrm{m} / \mathrm{s}^{2}\right)$. The angular velocity of the rotor must be calculated as follows:

$$
\omega=\frac{2 \pi N}{60}
$$

Where $N$ is revolution per minutes $(\mathrm{rpm})$

In other while for determining the moment coefficient on each turbine blade, first have to determine the swept area with equation (6) as follows:

$$
A=D H
$$

Where $A$ is swept area/aspect ratio $\left(\mathrm{m}^{2}\right), H$ is rotor height $(m)$. The swept area is also used for solving moment coefficients. The non-dimensional moment coefficient is calculated using equation (7) as follows:

$$
C_{m}=\frac{T}{\frac{1}{4} \rho A D V^{2}}
$$

Once the angular velocity is determined, the tip-speed ratio of the rotor is solved from equation (8).

$$
\lambda=\frac{\omega D}{2 V}
$$

The non-dimensional term for comparing efficiency of VAWTs is the power coefficient. The Power coefficient $C_{p}$ can be determined from the following Equation:

$$
C_{p}=\frac{P_{m}}{P_{w}}
$$

Where $P_{w}$ is calculated from the following equation:

$$
P_{w}=\frac{1}{2} \rho A V^{3}
$$

Finally, based on equation (2), (3), (4), (5), (9) and (10) the power coefficient can be formulated as:

$$
C_{p}=\frac{\operatorname{gr\pi n}(m-s)}{15 \rho A V^{3}}
$$

The power coefficient is also found from the product of tip-speed ratio and moment coefficient.

$$
C_{p}=\frac{P}{\frac{1}{2} \rho A V^{3}}=\frac{T \omega}{\frac{1}{2} \rho A V^{3}}=\lambda C_{m}
$$

\section{RESULTS AND DISCUSSION}

Figure 4 shows the result of experimental of the power coefficient of turbine as function of Tip Speed Ratio, for $\mathrm{S} / \mathrm{D}=1.4$ and $\mathrm{Re}=127,000$. The Figure show that, in general compared to conventional Savonius wind turbines, the placement of a I- $65^{\circ}$ type cylinder in front of 


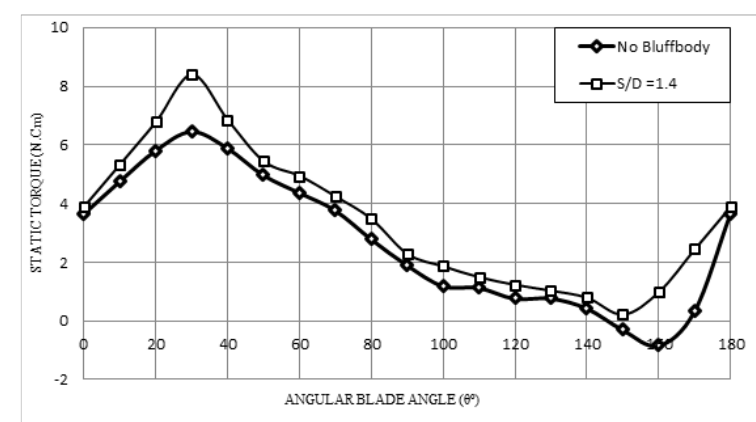

Figure 6. Evolution of the static torque $(\mathrm{Ncm})$ as a function of the blade angle $(\theta)$ for $\mathrm{Re}=127.0000$, comparison between the

Savonius turbine without and with I- $65^{\circ}$ cylinder bluff body for $\mathrm{S} / \mathrm{D}=1.4$.

the returning blade Savonius wind turbine is effective for improving turbine performance. The results of this experiment show that for $\operatorname{Re}=127,000$, the power coefficient of the turbine with the I- $65^{\circ}$ type cylinder is greater than when the turbine has no I- $65^{\circ}$ type cylinder or conventional Savonius wind turbine. Where in this condition, the power coefficient of the turbine $(\mathrm{CP})$ with I- $65^{\circ}$ cylinder type can actually increase to $25.66 \%$ of the turbine without the I- $65^{\circ}$ cylinder type, this is obtained for Tip Speed Ratio of 0.76 .

Figure 5 demonstrates that the improvement torque coefficient is observed throughout for all values of tip speed ratio compared to the conventional Savonius turbine. This figure shows that torque coefficient $\left(C_{m}\right)$ is even higher for lower tips-speed ratio $(\lambda)$ values and significant increase for placement $\mathrm{I}-65^{\circ}$ type cylinder bluffbody $\mathrm{S} / \mathrm{D}=1.4$.

One of the important consideration factors associated with wind energy is its self-starting capability. To investigate this issue, the static torque exerted on the turbine at a several fixed angles has been computed by LUTRON model TQ-8800 experimentaly as a function of the angular position of the rotor $(\theta)$.

Figure 6 shows the static torque obtained as function of the angle $(\theta)$ for $\operatorname{Re}=127.000$, and it is in comparison between the static torque of the conventional turbine and that of turbine with I- $65^{\circ}$ type cylinder bluffbody as disturbance for distance of $\mathrm{S} / \mathrm{D}=1.4$. Consider to periodicity, graphic only plot ranged from $0^{\circ}$ to $180^{\circ}$. This figure shows that placing bluffbody upstream returning blade has considerable and positive effect on the static torque coefficient. Conventional Savonius has particular negative value arround $\theta=150^{\circ}-$ $170^{\circ}$ that its confirmed by [4], as no self-starting. In the present, negative torque region disappeared by bluffbody configuration $\mathrm{S} / \mathrm{D}=1.4$, with minimum value of $T s$ higher than 0.2 N.cm.

\section{CONCLUSION}

The Savonius turbine is a promising concept for smallscale wind energy systems, but suffers from a poor efficiency. Therefore, the major objective of the present study is to develop an improved design, leading to higher values of the power coefficient and of the static torque of the Savonius turbine, thus obtaining a higher efficiency and better self-starting capability.

For this purpose, bluffbody cylinder I- $65^{\circ}$ type installed as a passive control at the upstream of returning blade specified at the relative position center to center $S / D=1.4$ then compared to the conventional Savonius wind turbine.

The installation of bluff body $\mathrm{I}-65^{\circ}$ type $(\mathrm{d} / \mathrm{D}=0.5)$ as passive control at the upstream of the returning blade (S/D $=1.4$ ) of the Savonius turbine for $\operatorname{Re}=127,000$ is effective to impove the performance of the turbine. Where in this condition the maximum coefficient of power (CP) of the turbine with bluff body $\mathrm{I}-65^{\circ}$ type cylinder can actually increase to $25.66 \%$ compared to the turbine without the bluff body I- $65^{\circ}$ type cylinder; this is obtained for Tip Speed Ratio of 0.76 .

This installation of bluffbody cylinder type I- $65^{\circ}$ is able to identify considerably better configurations than the standard Savonius turbine, leading in particular to the static torque as turbine self starting capability. The bluffbody effective to increase static torque at any angle and disappear negative value within $150^{\circ}-170^{\circ}$ position angle.

\section{REFERENCES}

[1] K. Morshed, "Experimental and numerical investigations on aerodynamic characteristics of Savonius wind turbine with various overlap ratios," 2010.

[2] Y. Triyogi, D. Suprayogi, and E. Spirda, "Reducing the drag on a circular cylinder by upstream installation of an I-type bluff body as passive control," J. Mech. Eng. Sci., vol. 223, no. 10, pp. 2291-2296, 2009.

[3] B. Altan, M. Atılgan, and A. Özdamar, "An experimental study on improvement of a Savonius rotor performance with curtaining," Exp. Therm. fluid Sci., vol. 32, no. 8, pp. 16731678,2008

[4] M. Mohamed, G. Janiga, E. Pap, and D. Thévenin, "Optimization of Savonius turbines using an obstacle shielding the returning blade," Renew. Energy, vol. 35, no. 11, pp. 2618-2626, 2010.

[5] N. Mahmoud, A. El-Haroun, E. Wahba, and M. H. Nasef, “An experimental study on improvement of Savonius rotor performance," Alexandria Eng. J., vol. 51, no. 1, pp. 19-25, 2012.

[6] T. Yuwono et al., "Numerical study on the effect of width of single curtain on the performance of Savonius wind turbine," in MATEC Web of Conferences, 2018, p. 1110.

[7] T. Yuwono et al., "The effect of width of single curtain on the performance of Savonius wind turbine," in AIP Conference Proceedings, 1983, p. 20023. 